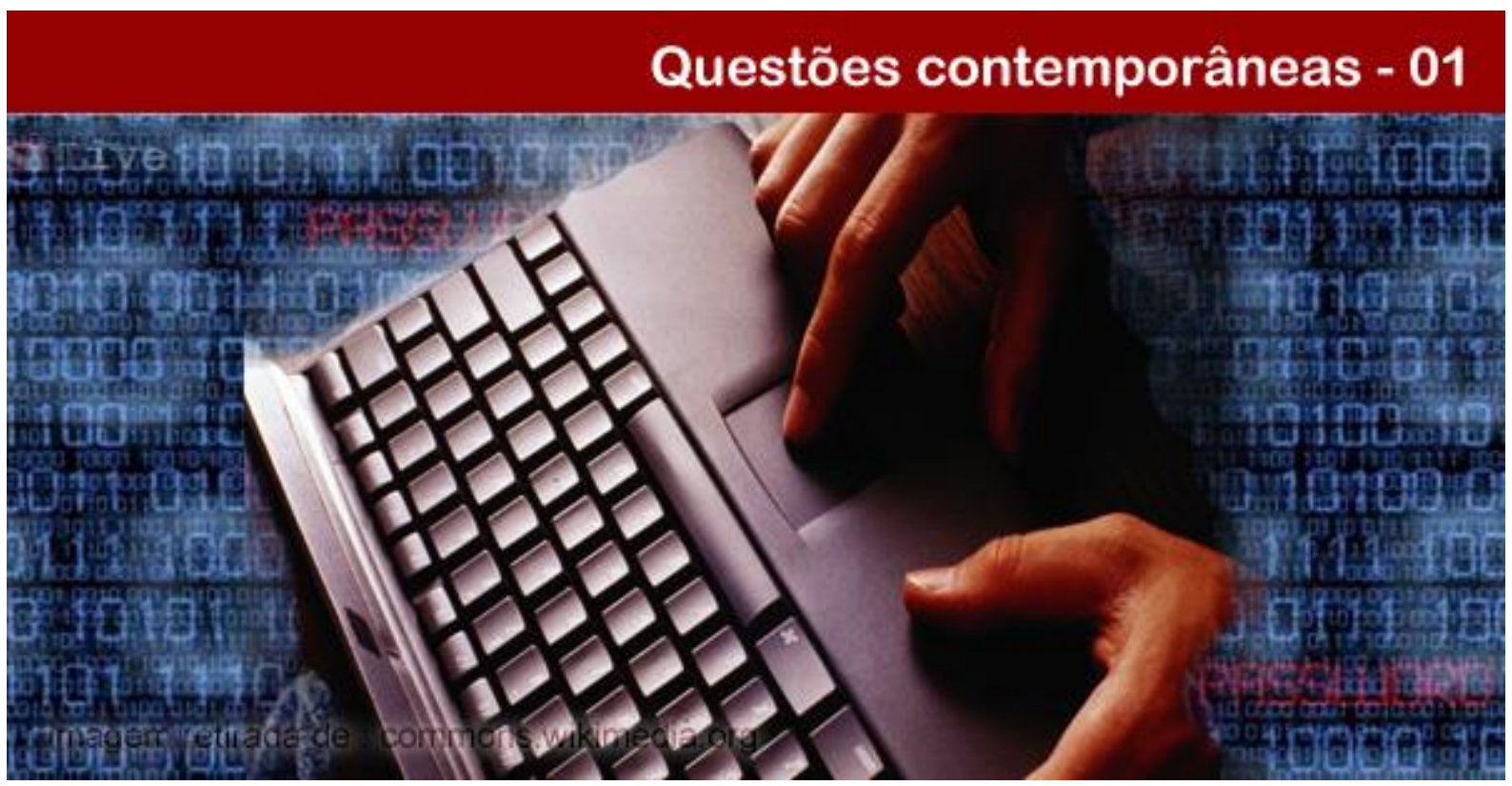

\title{
“A QUEBRADA ESTÁ ONLINE": ANÁLISE DO USO DAS REDES SOCIAIS POR ADOLESCENTES COM HISTÓRICO DE ENVOLVIMENTO EM ATOS INFRACIONAIS
}

\begin{abstract}
Alex Sandro Gomes Pessoa
Graduado em Psicologia pela Universidade do Oeste Paulista (UNOESTE). Licenciado em Educação Física, Mestre e Doutor em Educação pela Universidade Estadual Paulista (UNESP). Vinculado à Faculdade de Psicologia e ao Programa de Pós-Graduação em Educação da UNOESTE. Pós-Doutorando em Psicologia na Universidade Federal do Rio Grande do Sul (UFRGS). Líder do "Grupo de Pesquisa com População em Situação de Vulnerabilidade Social" (GPPVS). Representante Latino-americano no Conselho da "International Association for the Promotion and Dissemination of Research on Resilience" (Resilio). E-mail: alexpessoa2@gmail.com.
\end{abstract}

\section{Vinícius Willian da Costa Branquinho}

Graduado em Psicologia pela Universidade do Oeste Paulista (UNOESTE) e Mestrando em Educação pela Universidade Estadual Paulista (UNESP). E-mail: viniciusw_branquinho@hotmail.com.

Resumo: Este artigo tem como objetivo analisar a relação de adolescentes com histórico de envolvimento em ato infracional com as redes sociais. Trata-se de uma pesquisa de caráter exploratória e descritiva, fundamentada na abordagem qualitativa. Buscou-se a compreensão dos sentidos e significados das redes sociais e dos recursos tecnológicos disponíveis para adolescentes em cumprimento de medidas socioeducativas. A pesquisa de campo foi realizada em um Centro de Referência em Assistência Social (CREAS) de um munícipio de pequeno porte localizado no interior do Estado de São Paulo. O grupo foi constituído por 5 (cinco) adolescentes, de 12 a 18 anos, sendo 4 meninos e 1 menina. Foi realizada uma entrevista semiestruturada, bem como foi utilizada a técnica da entrevista reflexiva. O conteúdo foi gravado em dispositivo eletrônico e, em seguida, o material coletado passou por um processo de transcrição na íntegra e as análises foram organizadas a partir da análise de conteúdo. Os resultados foram organizados em 4 (quatro) temáticas: 1) Acessibilidade a recursos tecnológicos e as redes sociais; 2) Relacionamentos interpessoais mediados pela tecnologia; 3) Atividades de interesse e sentidos pessoais em relação às redes sociais; 4) Ato infracional e uso de redes sociais. Entende-se que os achados desta investigação podem auxiliar profissionais que atuam com adolescentes na implantação de estratégias socioeducativas que dialoguem com as culturas juvenis e que impliquem no uso racional, consciente e mais saudável das redes sociais.

Palavras-chave: Adolescência. Redes sociais. Ato infracional.

\section{POLÊM!CA LABORE (')}

Polêmica - Revista Eletrônica da Uerj - Rua São Francisco Xavier, 524, $1^{\circ}$ andar bloco D, sl.1001 • Tels.: +55 21 2334-4088/4087 • http://www.e-publicacoes.uerj.br/index.php/polemica/index http://www.labore.uerj.br • laboreuerj@yahoo.com.br 


\title{
ANALYSIS OF THE USE OF SOCIAL NETWORKS BY YOUNG OFFENDERS
}

\begin{abstract}
This article aims to analyze the relationship of young offenders with the social networks. It is an exploratory and descriptive research, based on the qualitative approach. We sought to understand the meanings of social networks and technological resources available to adolescents who were in the correction system. The fieldwork was carried out in an institution for young offenders located in a small city in the inner of Sao Paulo State, Brazil. The group consisted of 5 (five) adolescents, from 12 to 18 years old, more specifically 4 boys and 1 girl. A semi-structured interview was conducted, as well as the reflexive interview technique was employed. The content was recorded by an electronic device and then the material went through a fully transcription process. The analyses were organized through the content analysis perspective. The findings were organized into 4 (four) thematic: 1) Accessibility to technological resources and social networks; 2) Interpersonal relationships mediated by the technology; 3) Activities of interest and personal senses in regarding social networks; 4) Delinquency and its relation with social network. The findings of this paper can help professionals who work with young offenders in the implementation of socio-educational strategies that dialogue with youth cultures and that involve the rational, conscious and healthier use of social networks.
\end{abstract}

Keywords: Adolescence. Social networks. Offenders.

\section{Introdução}

O advento das redes sociais tem sido objeto de estudos no meio acadêmico, especialmente no campo das Ciências Humanas e Sociais (CARRERA, 2012). Pode-se afirmar, com base na literatura, que o desenvolvimento de comunidades e redes sociais online é um dos maiores acontecimentos dos últimos anos, sobretudo porque constituiu uma nova maneira de organização das relações sociais. As redes virtuais têm estabelecido novas configurações nas relações interpessoais e, consequentemente, na maneira de ser do homem em toda sua complexidade individual e social. Assim, compreende-se que a internet e seus diversos recursos trouxeram implicações e mudanças drásticas nas relações humanas.

Entre as ferramentas mais populares, destacam-se as redes de interação que se configuram como locais virtuais de troca constante entre as pessoas, denominadas redes sociais. Conforme Rosa e Santos (2013), “entre as principais funções das redes sociais de Internet, encontram-se a possibilidade de comunicar-se com outras pessoas, de estabelecer e de manter contatos" (p. 9). As redes sociais são diversas e aumenta cada dia o número de usuários que acessam suas ferramentas. Entre as principais, aparecem o Facebook, Twitter, Instagram, Snapchat, Whatsapp, entre outros. Todas estas redes permitem um acesso constante, produzindo novas modalidades de relações que interferem na constituição das subjetividades (NOBREGA, 2010).

Entende-se que o processo de construção da subjetividade dos seres humanos é constante. $\mathrm{O}$ homem se constituiu a partir do processo de hominização que provém da sociedade e da cultura (LEONTIEV, 1978). Tais atributos o diferenciam das demais espécies

\section{POLÊM!CA $\mid$ LABORE}

Polêmica - Revista Eletrônica da Uerj - Rua São Francisco Xavier, 524, $1^{\circ}$ andar

bloco D, sl.1001 • Tels.: +55 21 2334-4088/4087 • http://www.e-publicacoes.uerj.br/index.php/polemica/index

http://www.labore.uerj.br • laboreuerj@yahoo.com.br 
animais e corroboraram para um salto qualitativo em termos da própria constituição do psiquismo, o que inclui os elementos constituintes da subjetividade. Pela atividade o homem adapta a natureza, modificando-a a partir de suas necessidades, e isso altera os modos de vida e, consequentemente, sua maneira de conceber as coisas e a sua existência. Assim sendo, não se compreende a subjetividade como uma estrutura apriorística, cujos comportamentos são estruturados de forma passiva e descontextualizados.

É necessário compreender o ser humano numa perspectiva situada criticamente, que o vê em todas as suas dimensões, representado num sistema integrador do interno e do externo, tanto em sua dimensão social como individual que, por sua gênese, é também social (OZELLA, 2003). Portanto, não se compreende o ser humano fora de sua relação com o outro e não fragmenta o homem e seu psiquismo em partes.

Sendo os processos de subjetivação algo que não se finaliza, mas percorre toda existência, não há algo marcante que definiria toda a singularidade, como postulado por correntes da psicologia tradicional. A subjetividade, então, se constrói mediante todo um processo da integração de várias facetas sociais e individuais, não sendo constituída por outras naturezas a não ser aquela que a constitui socialmente. Desse modo, a subjetividade:

[...] é um sistema complexo de significações e sentidos subjetivos produzidos na vida cultural humana, e ela se define ontologicamente como diferente dos elementos sociais, biológicos ecológicos e de qualquer outro tipo, relacionados entre si no complexo processo de seu desenvolvimento (GONZALEZ-REY, 2013, p. 36-37).

As considerações apresentadas instigam pesquisadores do campo das ciências humanas a compreender os mecanismos que estão presentes na constituição de subjetividades de adolescentes que mantêm relações interpessoais pelas redes sociais e os sentidos atribuídos aos novos recursos tecnológicos presentes nas culturas juvenis (ASSUNÇÃO, MATOS, 2014). Parte-se do pressuposto que a comunicação constitui a subjetividade do homem, e nada mais algoz nessa trama do que as redes sociais, que imprimem na sociedade uma maneira particular do sujeito se constituir.

Ao reconhecer que as redes sociais interferem de maneira substancial no modo de ser e agir de adolescentes, destaca-se a necessidade de pesquisas que investiguem a relação de adolescentes com histórico de envolvimento em atividades ilícitas e que estão em cumprimento de medidas socioeducativas por acometimento de ato infracional. As medidas socioeducativas são ações intersetoriais (sistema judiciário, políticas de educação, saúde,

\section{POLÊM!CA $\mid$ LABORE}


assistência social, entre outros) que buscam a reinserção social do adolescente com envolvimento em atos infracionais, bem como prima pela prevenção de reincidências (MONDINI, 2011; NARDI; DELL'AGLIO; 2012). As medidas aplicadas se subdividem em: a) advertência, b) reparação de dano, c) prestação de serviços à comunidade, d) liberdade assistida, e) semiliberdade, f) e, por fim, internação (BRASIL, 2006).

O envolvimento de adolescentes em atividades ilícitas tem se mostrado uma das principais pautas de discussões no plano político atual. Entretanto, os discursos de senso comum ainda parecem fundamentar boa parte dos debates, não apenas da população em geral, mas de setores da sociedade que deveriam embasar suas propostas com argumentos científicos e filosóficos. Nesse sentido, as universidades, os pesquisadores e as pessoas envolvidas com as políticas públicas devem articular-se, no sentido de criar estratégias para apresentar propostas que sejam benéficas a toda população, em especial aos próprios adolescentes.

Nesta empreitada, evidencia-se a necessidade de compreender o contexto de vida dos adolescentes a partir de várias frentes. A caracterização das realidades da cultura juvenil, em especial de adolescentes com histórico de envolvimento em atos infracionais, pode colaborar de maneira assertiva na elaboração de modelos interventivos e na implantação de ações mais efetivas no combate à reincidência ao ato infracional. Assim, compreender os interesses subjetivos, as relações interpessoais, os projetos de vida, as aspirações e o acesso a bens culturais são alguns dos temas relevantes para o entendimento da realidade desta população.

Com base nestes argumentos, este artigo tem como objetivo analisar a relação de adolescentes com histórico de envolvimento em ato infracional com as redes sociais. Buscouse caracterizar desde os indicadores de acesso até as principais atividades realizadas. Entendese que a elaboração de um corpo de conhecimento a partir dessa investigação pode colaborar na sistematização de ações que estejam mais alinhadas com a realidade dos adolescentes supracitados.

\section{Método}

Esta investigação, de caráter exploratória e descritiva, optou pela abordagem qualitativa. Buscou-se a compreensão dos sentidos e significados das redes sociais e dos recursos tecnológicos disponíveis para adolescentes em cumprimento de medidas

\section{POLÊM!CA $\mid$ LABORE}


socioeducativas na modalidade de Liberdade Assistida (LA). A abordagem adotada permitiu aos pesquisadores uma compreensão do fenômeno a partir da perspectiva dos participantes do estudo. Estudiosos que investigam a realidade de crianças e adolescentes têm insistido na necessidade de compreender os fenômenos sociais e subjetivos a partir da perspectiva das populações infanto-juvenis (GROUNDWATER-SMITH, DOCKETT, BOTTRELL, 2015; CHRISTENSEN, JAMES, 2005). A desvalorização da participação dessa população em estudos implica na parcialidade da construção do conhecimento, que hipervaloriza determinados vieses explicativos em detrimentos de outros.

\section{$\underline{\text { Local da pesquisa e participantes }}$}

A pesquisa de campo foi realizada em um Centro de Referência em Assistência Social (CREAS) de um munícipio de pequeno porte localizado no interior do Estado de São Paulo. Há somente um serviço como este na cidade, sendo a instituição responsável por toda a demanda de média complexidade encaminha aos órgãos públicos. A equipe de atendimento psicossocial, que auxiliou no contato com os participantes, é composta por assistente social, assessora jurídica, psicóloga e coordenadora.

Os participantes foram adolescentes em cumprimento de medidas socioeducativas que cumpriam LA. Trata-se de uma medida socioeducativa prevista no Estatuto da Criança e do Adolescente (Lei $\mathrm{n}^{\circ}$ 8.069/90) (BRASIL, 1995), onde o adolescente em conflito com a lei deve ser acompanhado por profissionais que o auxiliem em sua inserção em práticas sociais diversas, que evitem a reincidência do adolescente. A LA é a medida socioeducativa mais aplicada e mais recorrente nos serviços de atendimento a essa população e "consiste em acompanhamento periódico do adolescente, por prazo mínimo de seis meses, sendo cabível sua prorrogação" (SIQUEIRA NETO et al, 2012 p. 116).

Após convite realizado a todos adolescentes que estavam em atendimento, constitui-se um grupo com 5 (cinco) adolescentes, de 12 a 18 anos $(\mathrm{M}=15,8 ; \mathrm{DP}=0,74)$, sendo 4 meninos e 1 menina. A amostragem foi intencional e levou em consideração os seguintes critérios: a) ter cometido ato infracional; b) estar vinculado ao CREAS e em cumprimento de LA; c) apresentar os Termos de Consentimento Livre e Esclarecido (TCLE) assinado pelos responsáveis do adolescente e o termo de assentimento (TA) assinado por eles próprios. A Tabela 1 apresenta a caracterização dos participantes:

\section{POLÊM!CA $\mid$ LABORE}


Tabela - 1: Caracterização dos participantes do estudo

\begin{tabular}{lcccc}
\hline Participantes & Idade & $\begin{array}{c}\text { Ato infracional } \\
\text { cometido }\end{array}$ & $\begin{array}{c}\text { Histórico de } \\
\text { reincidência }\end{array}$ & $\begin{array}{c}\text { Pessoas com quem } \\
\text { mora atualmente }\end{array}$ \\
\hline André & 17 & Tráfico & Não & $\begin{array}{c}\text { Pai, mãe e dois } \\
\text { irmãos }\end{array}$ \\
Hugo & 16 & Tráfico & Não & Bisavós e irmãos \\
Leandro & 16 & Tráfico & Não & Avós \\
Sílvia & 15 & Contra dignidade sexual & Não & $\begin{array}{c}\text { Mãe, avó e duas } \\
\text { irmãs } \\
\text { Igor }\end{array}$ \\
\hline
\end{tabular}

Fonte: Os autores (2017).

\section{$\underline{\text { Instrumento }}$}

Foi utilizado um roteiro de entrevista semiestruturado construído a partir de elementos trazidos pela literatura da área, em especial fundamentado em pesquisas que analisaram os sentidos das tecnologias e redes sociais no contexto da adolescência (BERNETE, 2010; ENCINAS; GONZÁLEZ, 2010). As questões versavam sobre a intensidade de uso das redes sociais, as atividades de interesse, níveis de interação e o uso dessas tecnologias para ações que se configuram como ato infracional ou contravenção penal.

Também foi utilizada a técnica da entrevista reflexiva (YUNES; SYMANSKI, 2005). Esta ação consiste na realização de entrevistas complementares àquelas realizadas no primeiro encontro com o participante. Estabelece-se, assim, mais de um encontro, cujos pesquisadores, após transcrever literalmente a primeira entrevista, podem retomar conteúdos trazidos pelos participantes e discutir as impressões que obtiveram. $\mathrm{O}$ intuito é promover o aprofundamento nos dados coletados nos primeiros contatos, ou ainda esclarecer aspectos que ficaram obscurecidos nos procedimentos de análise. Tais recursos permitem que as interpretações conduzidas pelos pesquisadores sejam menos enviesadas e mais comprometidas com o desvelamento dos sentidos reais que os participantes possuem. Trata-se de uma técnica recomendável a populações em situação de vulnerabilidade, adolescentes e crianças, que muitas vezes têm suas vozes silenciadas ou até mesmo são submetidos a modelos explicativos que não retratam fidedignamente suas realidades.

$\underline{\text { Procedimentos e análise dos dados }}$

\section{POLÊM!CA $\mid$ LABORE}

Polêmica - Revista Eletrônica da Uerj - Rua São Francisco Xavier, 524, $1^{\circ}$ andar

bloco D, sl.1001 • Tels.: +55 21 2334-4088/4087 • http://www.e-publicacoes.uerj.br/index.php/polemica/index http://www.labore.uerj.br • laboreuerj@yahoo.com.br 
As entrevistas ocorreram no próprio CREAS, durante o horário de atendimento semanal dos adolescentes. A equipe da instituição auxiliou no contato com os participantes, estabelecendo o contato por telefone para lembrá-los dos dias agendados da pesquisa. As entrevistas foram individuais e conduzidas pelo segundo autor deste artigo, incluindo as entrevistas reflexivas. O conteúdo foi gravado por um dispositivo eletrônico e, em seguida, o material coletado passou por um processo de transcrição na íntegra.

As análises foram inspiradas no modelo proposto por Bardin (2009) de análise de conteúdo. Esses procedimentos permitiram a organização de temáticas a partir de núcleos semânticos que emergiram na fala dos participantes, que estavam associadas à problemática central do estudo. As temáticas foram organizadas pelos autores de forma independente. Em seguida, os mesmos discutiram as similaridades encontradas e, em comum acordo, selecionaram trechos que reportavam de maneira clara e sem dubiedades aspectos relevantes para o campo investigativo em questão. $\mathrm{Na}$ última fase da análise de dados, as temáticas foram submetidas à Análise de Concordância entre Juízes, através de uma comissão constituída por pesquisadores com notória experiência na área e que não haviam participado de nenhuma etapa precedente.

\section{Questões éticas}

A pesquisa se baseou nas diretrizes estabelecidas pela resolução 466/2012 do Conselho Nacional de Saúde, que define os critérios de pesquisa que envolve seres humanos. Dessa maneira, os responsáveis pelos adolescentes expressaram concordância quanto aos procedimentos adotados por meio de assinatura do Termo de Consentimento Livre e Esclarecido (TCLE). Além disso, os adolescentes assinaram o Termo de Assentimento (TA), que versava sobre a adesão voluntária no projeto, o não recebimento de recompensas financeiras e os objetivos traçados para o estudo em questão. $\mathrm{O}$ projeto de pesquisa foi avaliado pelo Comitê de Pesquisa com seres Humanos da Universidade do Oeste Paulista (UNOESTE) e recebeu parecer favorável quanto à sua realização (CAEE 45618115.2.0000.5515). Por fim, cabe salientar que os nomes dos participantes apresentados nesse artigo são fictícios, com vistas a preservar a identidade dos adolescentes.

\section{Resultados e discussão}

\section{POLÊM!CA $\mid$ LABORE}


A análise de conteúdo revelou 4 (quatro) temáticas que estão relacionados com o objeto de estudo delimitado na investigação: 1) Acessibilidade a recursos tecnológicos e as redes sociais; 2) Relacionamentos interpessoais mediados pela tecnologia; 3) Atividades de interesse e sentidos pessoais em relação às redes sociais; 4) Ato infracional e uso de redes sociais. Cada temática foi elaborada com respaldo nas falas dos participantes, captadas durante a etapa de condução das entrevistas. Desse modo, optou-se em apresentar trechos literais, objetivando aproximar o leitor da realidade dos adolescentes e da unidade de análise desenvolvida.

\section{$\underline{\text { Acessibilidade a recursos tecnológicos e redes sociais }}$}

Nessa temática, avaliou-se o nível de acessibilidade e os diferentes recursos que os adolescentes dispunham para o acesso às redes sociais. Os resultados apontam que todos os participantes fazem uso das redes sociais, sobretudo o Facebook e Whatsapp. O acesso se dá, majoritariamente, em equipamentos particulares, como computadores instalados nas próprias residências, celulares próprios ou de pessoas próximas aos adolescentes, especialmente das mães.

A intensidade do uso varia entre os participantes, embora todos tenham afirmado que utilizam diariamente. Constatou-se que a disponibilidade de conexão com a internet é a variável mais significativa para a frequência de acesso as redes sociais. Em alguns casos, parece haver um controle sobre o uso, que é intercalado com outras atividades sociais (Hugo: "Ahh, a hora que tipo, eu não estiver fazendo nada ali, eu sempre vou estar no celular" / Adriano: "Era skatista e tal, andava o dia inteiro, aí chegava em casa e ficava madrugada inteira no computador e no outro dia dormia o dia inteiro”). Mas para alguns adolescentes o acesso às redes sociais é intenso e parece ocupar boa parte da rotina (Igor: "Uso a manhã toda. Se eu estiver em casa, a tarde toda também").

Quanto à conexão, foram mencionados os pacotes de dados disponibilizados pelas companhias telefônicas, mas prevalece o uso do wifi (Igor: "Enquanto eu estou no wifi eu fico mexendo no whatsapp, no face ou os dois ao mesmo tempo [...] pelo $3 G$ também, quando eu coloco crédito”). Os participantes apontaram que seus celulares se conectam com redes de internet em vários espaços, entre eles, na própria residência, na casa de parentes e amigos mais próximos e também em espaços públicos que a prefeitura disponibiliza à população.

\section{POLÊM!CA $\mid$ LABORE}


Hugo: Eu uso [wifi da praça pública] quando eu saio no final de semana [...] Na rodoviária tem. É bom também. Eu corto cabelo lá e já mexo no wifi [...] eu ia na casa do meu primo pra entrar, na praça, ia pra algum lugar, mas sempre tinha que estar conectado ali no celular.

Alguns participantes mencionaram que utilizam os celulares das mães porque não têm condições de comprar seus próprios (Adriano: "Uso facebook mesmo [...] pelo celular da minha mãe também [...] saí da fundação [Fundação Casa] esses dias, está apertado pra minha mãe também”). Afirmaram, ainda, que alguns programas não foram instalados nos celulares por conta da incompatibilidade do dispositivo, uma vez que alguns programas requerem equipamentos mais modernos e atualizados (Hugo: "Uso facebook e whatsapp [...] todo dia. Instagram não dá pra instalar no meu celular, senão...”).

$\underline{\text { Relacionamentos interpessoais mediados pelas redes sociais }}$

Foram considerados, nesta temática, excertos que se referem aos relacionamentos interpessoais estabelecidos pelos participantes, tendo como mediação as redes sociais. Foi possível identificar dois núcleos centrais, que revelam a função das redes sociais nos relacionamentos entre pares e também nas relações afetivo-sexuais (namoro, paquera, entre outros) dos participantes.

Sobre os relacionamentos entre pares, verificou-se que os adolescentes utilizam as redes sociais para marcarem encontros presencias, que parecem ser mais valorizados do que os chats ou espaços virtuais de interação. Eles também avaliam que não existem diferenças no modo de agir das pessoas no mundo real e virtual (Hugo: “[...] é dificil, ver pessoas assim que mudam [...] ou também ela muda por motivos né, tipo, ciúmes ou está bravo, tipo porque aconteceu alguma coisa”).

Embora a interação possibilitada pelas redes sociais tenha sido valorizada pelos adolescentes, também foram encontrados diversos relatos de violência nas entrevistas. Os eventos foram descritos envolvendo outras pessoas, mas também surgiram detalhes de práticas promovidas pelos próprios adolescentes (Igor: “[...] da hora também, um zoando com o outro. Até eu faço montagem dos moleques lá, dos moleques parecendo viado [risos]. Coloco peruca, coloco batom, coloco brinco, uns colarzinhos, um negócio na cabeça”). Relataram que conhecem pessoas que tiveram sua imagem exposta e vários problemas ocorridos posteriormente. Além disso, afirmam que muitos colegas usam as redes sociais para

\section{POLÊM!CA $\mid$ LABORE}

Polêmica - Revista Eletrônica da Uerj - Rua São Francisco Xavier, 524, $1^{\circ}$ andar

bloco D, sl.1001 • Tels.: +55 21 2334-4088/4087 • http://www.e-publicacoes.uerj.br/index.php/polemica/index http://www.labore.uerj.br • laboreuerj@yahoo.com.br 
provocar ou "dar indiretas" a pessoas que não gostam. Essas verbalizações mostram que as redes sociais podem promover situações de constrangimento para os participantes e outros conflitos sociais, tal como explicitado na fala de Adriano:

\begin{abstract}
Adriano: Nossa, bravo, fiquei com raiva. Tipo assim, ele postou tipo numa conta que eu tinha, entendeu? O "Ask", não sei se você conhece, um bang de perguntas anônimos. Aí eu tinha deixado esse Ask, quando eu andava de skate ainda, aberto no computador do moleque que eu estava na casa dele, colega meu. Daí, eu saí lá pra fora e eu já usava droga, que era maconha. Eu fui fumar maconha e deixei aberto, nem sabia que ele ia mexer. Ele foi lá e mandou pra todo mundo e pá, que eu queria dar a bunda, me zoando. Nossa, eu fiquei bravo, roubou minha brisa. Falei "nossa você está tirando? fica moscando". Ele dando risada e eu bravo, daí ele foi lá e apagou tudo, aí ficamos suave.
\end{abstract}

Em consonância com o que foi apresentado acima, constatou-se que as redes sociais trazem diversas implicações no modo de se relacionar dos participantes, inclusive em termos das relações afetivo-sexuais. Alguns participantes chegaram a afirmar que o início do namoro se deu por intermédio das redes sociais (Leandro: "Face e depois whats ajudou [...] bom, conheci, ela comentou minha foto, aí nós começamos a conversar. Depois nós marcamos de se encontrar, nos encontramos, até hoje está aí."). Também destacaram que o uso de aplicativos auxilia na aproximação e trouxe implicações frente aos relacionamentos afetivos, tal como expresso na fala de Sílvia:

\begin{abstract}
Sílvia: [...] antigamente eu conversava, os meninos conversavam comigo, morria de vergonha. Mas no facebook não, eu não tenho vergonha. Pessoalmente já tenho [...] tipo assim, no facebook eu não sinto vergonha, porque a gente não está se vendo, mas pessoalmente eu já sinto. [...] o menino veio conversar comigo. Perguntou se estava tudo bem e tal. Pelo facebook eu já não tinha vergonha, respondia tudo. Aí foi uma vez por telefone também, não tinha vergonha de nada, conversamos normal. Agora pessoalmente só dele falar "oi, tudo bem?" eu fico vermelha e começo a morrer de vergonha. Não sei por que eu sou assim [risos].
\end{abstract}

\title{
$\underline{\text { Atividades de interesse e sentidos pessoais em relação às redes sociais }}$
}

Esta temática é composta pela descrição das principais atividades realizadas nas redes sociais apontadas pelos adolescentes, bem como os sentidos pessoais atribuídos a elas. Os participantes afirmam que o Facebook é a rede social que eles mais interagem, pois permite que eles expressem suas opiniões sobre aquilo que eles gostam (fotos, frases de efeito e temas diversos). Falaram sobre jogos, salas de interação virtual, músicas e vídeos que são disponibilizados e / ou compartilhados nesses espaços. Também expressaram atividades de interesse que estão disponíveis nas redes sociais, como acompanhar o trabalho de tatuadores.

\section{POLÊM!CA | LABORE ( (3)}

Polêmica - Revista Eletrônica da Uerj - Rua São Francisco Xavier, 524, $1^{\circ}$ andar

bloco D, sl.1001 • Tels.: +55 21 2334-4088/4087 • http://www.e-publicacoes.uerj.br/index.php/polemica/index http://www.labore.uerj.br • laboreuerj@yahoo.com.br 
A ausência de outras atividades de lazer direcionadas à adolescência visivelmente é substituída por momentos de interação nas redes sociais (Leandro: "De tarde, às vezes que não tem nada pra fazer eu entro, mas é pouco, não gosto tarde” / Hugo: "Ah, a hora que tipo, eu não estiver fazendo nada ali, eu sempre vou estar no celular" / Sílvia: "Não, dia todo não, quando não tenho nada para fazer, eu fico mexendo no celular"). Desse modo, em consonância com a literatura, percebe-se que as tecnologias e as redes sociais podem estar suprindo a ausência de políticas de lazer para o grupo entrevistado.

Averiguou-se que, em alguns casos, as redes sociais permitem a expressão do pertencimento social, descrita de maneira positiva (Adriano: "Ah, tipo assim, colocar um exemplo: tiro uma foto e tem uns colegas meus na quebrada, onde que eu moro. 'Aqui de tarde com os quebrada e pá', 'Aqui de tarde com meus amigos e pá'. Aí posta a foto. É da hora”). Também foram registradas as possibilidades de os adolescentes expressarem nas redes sociais o senso identitário e suas preferências (Sílvia: “[...] bom, as imagens assim que eu concorde, umas coisas que concorde assim... música eu compartilho: funk, rap, reggae, tudo [...] só compartilho porque eu gosto mesmo”).

Ato infracional e uso das redes sociais

As redes sociais, que servem para agendar os encontros dos adolescentes e estabelecer relações interpessoais, também foram apontadas como o recurso utilizado para organizar atividades relacionadas ao ato infracional ou comportamentos ilícitos (Igor: "[...] combinar de beber de vez em quando [...] no facebook não, pelo whats já, várias vezes [...] só fumo maconha, mas em lugar escondido, não no meio da rua, pra ninguém ver”). Os adolescentes apontam que a comunicação deve ser cautelosa, pois acreditam que a polícia já possui estratégias de vigilância que podem comprometê-los (Hugo: "[se] a polícia ver já [as conversas], quer falar que é aquilo né, que mexe com alguma coisa”).

Com base nestas constatações buscou-se, nesta temática, uma relação entre atividades que se configuram como ato infracional e a relação com o uso das redes sociais. Cabe reforçar que dos atos infracionais cometidos pelos entrevistados, quatro tiveram um histórico com o tráfico de drogas e uma relação direta com o uso das redes sociais. Dos cinco adolescentes, apenas Sílvia não apresentou nas entrevistas associações entre atos infracionais e redes sociais. Um dos adolescentes afirmou que, na época em que traficava, ouvia sobre a

\section{POLÊM!CA $\mid$ LABORE}


possibilidade da comercialização de substâncias psicoativas por intermédio das redes sociais. Já o participante André afirma, explicitamente, ter usado esta estratégia para o tráfico:

Pesquisador: Você usava as redes sociais pra vender?

André: Usava

Pesquisador: Como era esse uso?

André: Ah tipo assim, tinha alguns nóias, usuários, que tinha aparência de boy, entendeu? Você nem imagina que o cara faz isso. Daí chamava no facebook: "Tem pá?". Aí respondia: “Tem, só encostar.” Entendeu? Alguns caras, tipo assim, só de olhar você não imagina nada desse cara, tá ligado?

Os participantes afirmam que as redes sociais, com seus aspectos ligados à agilidade na comunicação, podem consistir numa ferramenta lucrativa para o tráfico de drogas, por dinamizar a atividade e facilitar a comercialização (Hugo: “[...] estou num lugar aqui né, estou aqui na praça, aí tem alguém lá embaixo, aí precisa levar alguma coisa [alguma droga] pra pessoa lá em cima, aí vou chamar aquela pessoa porque ela tem, aí mandava mensagem”). Há, entretanto, um consenso entre os entrevistados em relação ao medo da utilização dos novos meios de comunicação para o tráfico de drogas, devido aos seus registros e pela possibilidade eminente de uma intervenção policial em suas contas privadas.

Leandro: [...] já fiquei sabendo de um moleque que tinha, que tinha conversa né... com outros moleques e foto dele fumando. Ai os policiais na hora que enquadrou viram as fotos. Ai levou e pegou o celular dele. Ele estava conversando com um moleque pra pegar.

Os adolescentes relatam o medo dos policiais entrarem em suas contas privadas (Leandro: "[...] por causa que redes sociais é perigosa, porque tem como entrar. Quando fui preso os policiais falaram mesmo que olhavam o que eu postava no face”). Há, portanto, o reconhecimento de que as redes sociais podem colaborar na comercialização das substâncias psicoativas, mas, simultaneamente, existe o receio do monitoramento dos policiais durante as abordagens ou mesmo nas investigações que realizam.

Afirmam, também, que a compra de drogas, tanto pessoalmente quanto por redes sociais, não é determinada por classe social ou pertencimento étnico, e que pessoas que não levantam suspeitas por parte da sociedade e da polícia realizam a compra de drogas. Ainda assim, relatam que a melhor maneira de vender drogas é, ainda, estabelecendo um ponto específico, pois os próprios usuários se encarregam em divulgar os locais de comercialização.

André: Só ficava parado no meu canto e eles vinham.

\section{POLÊM!CA $\mid$ LABORE}

Polêmica - Revista Eletrônica da Uerj - Rua São Francisco Xavier, 524, $1^{\circ}$ andar

bloco D, sl.1001 • Tels.: +55 21 2334-4088/4087 • http://www.e-publicacoes.uerj.br/index.php/polemica/index

http://www.labore.uerj.br • laboreuerj@yahoo.com.br 
Pesquisador: No face também?

André: Também.

Pesquisador: E como que eles sabiam que você vendia?

André: Ah tipo, notícia se espalha, você começa botar a cara e a notícia se espalha, entendeu? Daí todos ficam sabendo, polícia, nóia, usuário, todo mundo.

\section{Discussão}

A pesquisa de campo revelou que as redes sociais são utilizadas por adolescentes com histórico de envolvimento em atos infracionais, o que evidencia a necessidade de estudos que caracterizem essas relações. As pesquisas na área centram-se, majoritariamente, em aspectos de escolarização e tipificação do ato infracional (PESSOA, COIMBRA, 2016). Esse movimento, que enfatiza demasiadamente as trajetórias escolares em detrimento de outras práticas culturais juvenis, pode negligenciar temas relevantes para o encaminhamento de ações interventivas que estejam mais alinhadas com os interesses desses grupos. Explicita-se, desse modo, a necessidade de estabelecer recortes investigativos mais amplos e diversificados para a compreensão da realidade de adolescentes em conflito com a lei.

Entende-se fundamental romper com discursos fatalistas que desqualificam o uso das tecnologias na realidade de adolescentes e jovens, sobretudo em situação de exclusão social. Frias, Peres, Pereira, Negreiros, Paranhos e Leite (2014) afirmam que estudos direcionados a temáticas do uso das tecnologias podem auxiliar de maneira mais efetiva na elaboração de programas sociais voltados a grupos marginalizados. De fato, a pesquisa de campo com os adolescentes envolvidos em atos infracionais mostrou que os participantes utilizam as redes sociais e valorizam as interações que estabelecem nestes canais de comunicação. O combate à reincidência no ato infracional perpassa a compreensão dos interesses subjetivos dos adolescentes e da vinculação deste grupo a atividades sociais diversificadas que estejam em consonância com os próprios interesses. Exatamente por isto, faz-se necessário a criação de modelos interventivos que utilizem a tecnologia e as redes sociais como estratégia de inclusão e participação social.

Por outro lado, é necessário estabelecer críticas circunstanciadas à imposição posta para o uso das redes sociais. Alguns dos participantes relataram que não têm acesso a determinados programas e aplicativos por conta da falta de compatibilidade com os aparelhos celulares que requerem, constantemente, modelos mais atualizados, provocando a necessidade da aquisição de novos produtos. A literatura tem mostrado que o fetichismo mercadológico e o ideal de consumo impresso na adolescência se configura como um dos motivos que levam

\section{POLÊM!CA $\mid$ LABORE}


esse segmento ao acometimento do ato infracional (PESSOA, 2015; SPANO; BOLLAND, 2013; SOUZA; SILVA-ABRÃO; OLIVEIRA-ALMEIDA, 2011; STEVENS; MORASH; PARK, 2011). Desse modo, levanta-se como hipótese que a impossibilidade de compra de equipamentos mais modernos, como celulares, pode conduzir o adolescente a atividades ilícitas que geram capital necessário para a aquisição de tais produtos.

Advoga-se, ainda, pela disponibilização de redes de acesso à internet em espaços públicos, uma vez que os discursos coletados destacam positivamente os equipamentos sociais de lazer que oferecem esses recursos, como as praças públicas e espaços de socialização para adolescentes e jovens. $\mathrm{O}$ acesso aos recursos tecnológicos pode implicar em níveis de participação social inimagináveis, incluindo em movimentos em prol de ideais democráticos (VIEGAS, COELHO, POZZEBON, 2014). Na medida em que adolescentes com envolvimento em atividades ilícitas têm possibilidades de acessar dispositivos tecnológicos em espaços públicos, surge a possibilidade de rompimento com práticas de segregação.

Os dados provenientes do trabalho de campo mostram que os adolescentes, embora apresentem discursos valorativos das redes sociais, preferem agendar encontros presenciais com os pares, contrariando estudos como de Encinas e González (2010) e Mabres (2008). Estes achados também contrariam retóricas do senso comum e da própria comunidade acadêmica que, por vezes, dimensionam equivocadamente o valor dado por adolescentes à tecnologia e às redes sociais. Bernete (2010) pontua que é necessário analisar o uso das redes sociais por adolescentes em articulação com outros temas, como: possibilidades materiais de acesso, questões relativas ao gênero e etnia, pertencimento de classe social, temas de interesse subjetivos, entre outros. A partir de análises sistematizadas dessas correlações seria possível estabelecer com mais precisão o que leva um adolescente a estabelecer com mais frequência determinado tipo de relação interpessoal, seja presencial ou mediado pelas redes sociais.

Foram constatados relatos da manifestação de violência, em especial práticas discursivas que revelam a presença da violência psicológica, preconceito, homofobia, entre outros. Todavia, cabe destacar que estas ações não podem ser consideradas como cyberbullying, pois ocorreram de maneira pontual, não repetitiva e os agressores tinham suas identidades reveladas (sobre este assunto ver os trabalhos de BUELGA, CAVA, MUSITU, 2010; WAASDORP, BRADSHAW, 2015). Ainda assim, ressalta-se a necessidade de

\section{POLÊM!CA $\mid$ LABORE}


intervenção, tendo em vista que as práticas de violência nas redes virtuais podem trazer implicações comportamentais severas aos usuários (RANNEY, PATENA, NUGENT, SPIRITO, BOYER, ZATZICK, CUNNINGHAM, 2016). O contexto dos adolescentes com envolvimento em atos infracionais já é marcado por múltiplas formas de violência, sendo que as práticas coercitivas no âmbito virtual podem intensificar os mecanismos de vulnerabilidade desta população.

As relações afetivo-sexuais dos adolescentes também passam por mediações pelas interações nas redes sociais. Alguns participantes alegaram que são tímidos e vergonhosos, mas que as redes sociais os ajudam na abordagem e na revelação de sentimentos que nutrem pelas pessoas. Não foram encontradas na literatura da área, mesmo em estudos internacionais, investigações empíricas ou teóricas que articulassem o tema das relações afetivo-sexuais com o uso das redes sociais por adolescentes, tampouco associado com grupos que apresentam histórico de envolvimento em atos infracionais. Isso aponta para novos temas que carecem de investimentos por parte de pesquisadores de populações infanto-juvenis. Todavia, cabe salientar que a única adolescente que participou do trabalho de campo, enfatizou as relações afetivas estabelecidas, o que pode sugerir diferenças em relação ao gênero no que tange a utilização das redes sociais e o tipo de interação, tal como indicado no estudo de Ruiz e Río (2009). Ainda assim, os dados coletados não permitem que análises pormenorizadas sobre o assunto sejam compartilhadas neste manuscrito.

As atividades de interesse dos adolescentes nas redes sociais estão alinhadas com os marcadores sociais considerados normativos para o grupo etário. As salas de bate papo, os jogos online, programas de música e sites de tatuadores foram destacados como as ações e espaços mais recorrentes das interações. Contudo, destaca-se a possiblidade da expressão do senso identitário, na medida em que os participantes relatam que podem compartilhar nas redes sociais conteúdos com os quais se identificam e valorizam. O trabalho de Souza e Costa (2012) mostra que as ações governamentais e as vivências de adolescentes que cumprem medidas socioeducativas são permeadas por práticas coercitivas e com pouca valorização do repertório cultural dos adolescentes. Nesta pesquisa, constatou-se que as redes sociais podem se configurar como um espaço de manifestação dos aspectos da individualidade e de liberdade de expressão do grupo.

\section{POLÊM!CA $\mid$ LABORE}


Os adolescentes também afirmam que as redes sociais são utilizadas na impossibilidade de desenvolver outras atividades, o que pode estar correlacionado com a ociosidade de adolescentes e jovens moradores da periferia (BARBOSA-PEREIRA, 2016). Outro dado relevante são as postagens de valorização do bairro em que residem, nomeado pelos participantes como "a quebrada". As falas demonstram valorização das comunidades, que são apresentadas publicamente nas redes sociais como espaços de pertencimento e orgulho. Sabe-se que estes territórios são marcados por exclusão social, o que não apareceu em momento algum nas gravações das entrevistas. Isso pode significar o uso alienado da tecnologia, que pode representar uma realidade virtual que é distorcida ou que negligencia os marcadores sociais da exclusão presentes nestes contextos.

A relação das redes sociais com atos infracionais apareceu frequentemente na fala dos entrevistados. A única preocupação que demonstram é em relação ao registro que permanece, pois, segundo os adolescentes, a polícia pode identificá-los. Dessa forma, não há preocupação com a exposição nas redes sociais, mas apenas com as sanções e métodos punitivos que podem ocorrer por parte da polícia. Estes profissionais deixam de ser vistos como agentes protetores da infância e adolescência e passam a ocupar um espaço de descrédito da população (SOUZA, SILVA-ABRÃO, OLIVEIRA-ALMEIDA, 2011).

Embora as redes sociais possam ser ferramentas lucrativas e mais dinâmicas, sobretudo na comercialização de substâncias psicoativas, os adolescentes reconhecem que os registros deixados na rede e a possibilidade de identificação dos envolvidos aumentam os riscos para uma provável aplicação de medida socioeducativa. Por este motivo, afirmam que preferem ocupar um ponto físico na cidade, geralmente próximo às suas residências, para efetuar o comércio.

Por fim, constatou-se que os adolescentes utilizam as redes sociais para uma série de atividades que os colocam em situação de risco, como por exemplo, agendamento de encontros para utilização de substâncias psicoativas, em especial a maconha. É importante salientar que estes dados dão indicadores para as políticas de saúde mental, tendo em vista que o uso de substâncias psicoativas na adolescência deve ser tratado no âmbito das políticas de saúde (PEREIRA, SUDBRACK, 2008). Ainda assim, a pesquisa aponta para a necessidade de problematização com os adolescentes com histórico de envolvimento em ato infracional sobre o uso das redes sociais, que parecem ocupar um espaço ambíguo na vida dos

\section{POLÊM!CA $\mid$ LABORE}


participantes, demarcado por momentos de interação positiva, mas também por atividades que os colocam em situações de risco ao desenvolvimento.

\section{Considerações finais}

Seria precipitado afirmar que os dados retratados em todas as temáticas se referem a padrões de relacionamentos interpessoais exclusivos de adolescentes em conflito com a lei. O material empírico, em boa parte, mais parece descortinar aspectos da relação de adolescentes com as redes sociais de forma geral. Todavia, estudos comparativos devem ser conduzidos para a verificação dessas hipóteses. Buscou-se, na construção do manuscrito, enfatizar aspectos peculiares da população em questão e que podem abrir margem para outros recortes investigativos.

Entre as limitações da pesquisa destaca-se o número limitado de participantes, dada a abordagem de pesquisa utilizada, o que não permite que generalizações sejam realizadas. Estudos com recortes quantitativos, de inserção ecológica e longitudinal precisam ser conduzidos para melhor caracterizar a realidade investigada. Também é necessário pontuar a necessidade de aprofundar as análises nas questões de gênero que, por hipótese, trazem implicações acentuadas no objeto de estudo. Reconhece-se, desse modo, que várias lacunas foram deixadas para futuras investigações.

As considerações postuladas neste artigo não esgotam os debates, pelo contrário, abrem margem para uma série de questões necessárias para a compreensão da realidade de adolescentes com histórico de envolvimento em atos infracionais. Talvez o mérito deste trabalho tenha sido a articulação de temas que ainda não haviam sido explorados pela literatura da área. Entende-se que os achados desta investigação podem auxiliar profissionais que atuam com adolescentes na implantação de estratégias socioeducativas que dialoguem com as culturas juvenis e que impliquem no uso consciente e mais saudável das redes sociais.

\section{Referências}

ASSUNÇÃO, R. S.; MATOS, P. M. Perspectivas dos adolescentes sobre o uso do Facebook: um estudo qualitativo. Psicologia em Estudo, Maringá, v. 19, n. 3, p. 539-547, jul./set. 2014.

BARBOSA-PEREIRA, A. Os "rolezinhos" nos centros comerciais de São Paulo: Juventude, medo e preconceito. Revista Latinoamericana de Ciencias Sociales, Niñez y Juventud, Manizales, v. 14, n. 1, p. 545-557, jan./jul. 2016.

\section{POLÊM!CA $\mid$ LABORE}


BARDIN, L. Análise de Conteúdo. 4. ed. Lisboa: Edições 70, 2009.

BERNETE, F. Usos de las TIC, relaciones sociales y cambios en la socialización de las y los jóvenes. Revista de Estudios de Juventud, Logroño, v. 10, n. 88, p. 97-114, mar./mai. 2010.

BRASIL. Estatuto da criança e do adolescente (ECA). 5ª ed. São Paulo: Saraiva, 1995.

BRASIL. Sistema Nacional de Atendimento Socioeducativo (SINASE). 1. ed. Brasília: CONANDA, 2006.

BUELGA, S.; CAVA, M. J.; MUSITU, G. Cyberbullying: victimización entre adolescentes a través del teléfono móvil y de Internet. Psicothema, Asturias, v. 22, n. 4, p. 784-789, out./nov. 2010.

CARRERA, F. Instagram no facebook: Uma reflexão sobre ethos, consumo e construção de subjetividade em sites de redes sociais. Animus: Revista Interamericana de Comunicação Midiática, Santa Maria, v. 11, n. 22 , p. 148-164, jul./dez. 2012.

CHRISTENSEN, P.; JAMES, A. Investigação com crianças: perspectivas e práticas. 1. ed. Lisboa: Escola Superior de Educação de Paula Frassinetti, 2005.

ENCINAS, F. J. L.; GONZÁLEZ, S. M. V. Menores y nuevas tecnologías: conductas indicadoras de posible problema de adicción. Psicothema, Asturias, v. 22, n. 2, p. 180-188, abr./mai. 2010.

FRIAS, M. A. E.; PERES, H. H. C.; PEREIRA, V. A. G.; NEGREIROS, M. C.; PARANHOS, W. Y.; LEITE, M. M. J. Idosos em situação de rua ou vulnerabilidade social: facilidades e dificuldades no uso de ferramentas computacionais. Revista Brasileira de Enfermagem, Brasília, v. 67, n. 5, p. 766-72, set./out. 2014.

GONZALEZ-REY, F. La subjetividad em una perspectiva cultural-histórica: avanzando sobre un legado inconcluso. Revista CS, Cali, n. 2, p. 19-42, jan./jun. 2013.

GROUNDWATER-SMITH, S.; DOCKETT, S.; BOTTRELL, D. Participatory research with children and young people. 1. ed. Great Britain: Dorset Press, 2015.

LEONTIEV, A. O desenvolvimento do psiquismo. 1. ed. Lisboa: Horizonte, 1978.

MABRES, M. 'Dependencia del Messenger'. Cuadernos de Psiquiatría y Psicoterapia del Niño y del Adolescente, Logroño, n. 45-46, p. 153-166, 2008.

MONDINI, C. E. C. M. Resiliência e medidas socioeducativas: síntese dialética de múltiplas determinações. 2011. 220f. Dissertação (Mestrado em Educação/Educação Social) - Universidade Federal de Mato Grosso do Sul, Campus do Pantanal, 2011.

NARDI, F. L.; DELL'AGLIO, D. D. Adolescentes em conflito com a lei: percepções sobre a família.

Psicologia: Teoria e Pesquisa, Brasília, v. 28 n. 2, p. 181-191, abr./mai. 2012.

NOBREGA, L. P. A construção de identidades nas redes sociais. Fragmentos de Cultura, Goiânia, v. 20, n. 1/2, p. 95-102, jan./fev. 2010.

OZELLA, S. (Org.) Adolescências construídas: a visão da psicologia sócio-histórica. 1. ed. São Paulo: Cortez, 2003.

PEREIRA, S. E. F. N.; SUDBRACK, M. F. O. Drogadição e atos infracionais na voz do adolescente em conflito com a lei. Psicologia: Teoria e Pesquisa, Brasília, v. 24, n. 2, p. 151-159, abr./mai. 2008.

PESSOA, A. S. G. Trajetórias negligenciadas: Processos de resiliência em adolescentes com histórico de envolvimento no tráfico de drogas. Tese (Doutorado em Educação) - Universidade Estadual Paulista, Presidente Prudente, 2015.

\section{POLÊM!CA LABORE}

Polêmica - Revista Eletrônica da Uerj - Rua São Francisco Xavier, 524, $1^{\circ}$ andar

bloco D, sl.1001 • Tels.: +55 21 2334-4088/4087 • http://www.e-publicacoes.uerj.br/index.php/polemica/index

http://www.labore.uerj.br • laboreuerj@yahoo.com.br 
PESSOA, A. S. G., \& COIMBRA, R. M. O traficante não vai à escola: processos de escolarização de adolescentes com envolvimento no tráfico de drogas. Revista Educação em Questão, v. 54, n. 42, p. 190-117, set./dez., 2016.

RANNEY, M. L.; PATENA, J. V.; NUGENT, N.; SPIRITO, A.; BOYER, E.; ZATZICK, D.; CUNNINGHAM, R. PTSD, cyberbullying and peer violence: prevalence and correlates among adolescent emergency department patients. General Hospital Psychiatry, v.39, p.32-38, mai./abr. 2016.

ROSA, G.; SANTOS, B. Facebook e as nossas identidades virtuais. 1. ed. Brasília: Thesaurus Editora, 2013.

RUIZ, E. E.; RÍO, M. J. G. Jóvenes en las redes sociales virtuales: Un análisis exploratorio de las diferencias de género. Feminismo/s, v. 14, p. 87-105, dez. 2009.

SIQUEIRA NETO, Lélio Ferraz de; et al. Manual Prático das Promotorias de Justiça de Infância e Juventude. São Paulo: MPSP, 2012. 457 p.

SOUZA E. M.; SILVA-ABRÃO F. P.; OLIVEIRA-ALMEIDA, J. Desigualdade social, delinquência e depressão: Um estudo com adolescentes em conflito com a lei. Revista Salud Publica, Bogotá, v. 13, n. 1, p. 13-26, jan./fev. 2011.

SOUZA, L. A.; COSTA, L, F. Aspectos institucionais na execução da medida socioeducativa de internação. Revista Psicologia Política, São Paulo, v.12, n. 24, p.231-245, mai./ago. 2012.

SPANO, R.; BOLLAND, J. Disentangling the effects of violent victimization, violent behavior, and gun carrying for minority inner-city youth living in extreme poverty. Crime \& Delinquency, v. 59, n. 2, p.191-213, mar. 2013.

STEVENS, T.; MORASH, M.; PARK, S. Late-adolescent delinquency: Risks and resilience for girls differing in risk at the start of adolescence. Youth \& Society, v. 43, n. 4, p. 1433-1458, dez. 2011.

VIEGAS, M. A.; COELHO, T. R.; POZZEBON, M. Internet e participação: o caso do orçamento participativo digital de Belo Horizonte. Revista de Administração de Empresas, São Paulo, v. 54, n. 3, p. 296- 308, mai./jun. 2014.

YUNES, M. A. M.; SZYMANSKI, H. Entrevista reflexiva e grounded-theory: estratégias metodológicas para compreensão da resiliência em famílias. Revista Interamericana de Psicologia, Porto Alegre, v. 39, n. 3, p. 431-438, 2005.

WAASDORP, T. E.; BRADSHAW, C. P. The overlap between cyberbullying and traditional bullying. Journal of Adolescent Health, v.56, n. 5, p.483-48, mai. 2015.

Recebido em: 01/02/2017.

Aceito em: 30/06/2017.

\section{POLÊM!CA $\mid$ LABORE}

